\title{
SELF TUNNING FILTER FOR THREE LEVELS FOUR LEGS SHUNT ACTIVE POWER FILTER WITH FUZZY LOGIC CONTROLLER
}

\author{
Dahmane Djendaoui $^{a, *}$, Amar Benaissa $^{b}$, Boualaga Rabhi $^{c}$, \\ LAID ZeLLOUMA ${ }^{d}$ \\ ${ }^{a}$ University of Biskra, Electrical Engineering Department, BP 145 RP, 07000 Biskra, Algeria \\ ${ }^{b}$ University of Djelfa, LAADI Laboratory, $P B$ 3117, 17000 Djelfa, Algeria \\ ${ }^{c}$ University of Biskra, LMSE Laboratory, BP 145 RP, 07000 Biskra, Algeria \\ ${ }^{d}$ University of El-Oued, LEVRES Laboratory, BP 789, 39000 El-Oued, Algeria \\ * corresponding author: d.djendaoui@mail.univ-djelfa.dz
}

\begin{abstract}
The low harmonic distortion and reduced switching losses are the advantages of using the multilevel inverter. For this purpose, the three-level inverter is used in this paper as a three-phase four-leg shunt active power filter (SAPF). The SAPF is used to eliminate the harmonic current to compensate the reactive power current, and to balance the load currents under an unbalanced non-linear load. A fuzzy logic controller and self-tuning filters (STF) are used to control the active power filter $(\mathrm{APF})$ and generate the reference current. To demonstrate the validity of the proposed control strategy, we compared it with a conventional $p-q$ theory, under distortion voltage conditions and unbalanced non-linear load. The Matlab-Simulink toolbox is used to implement the algorithm of Fuzzy logic control. The performance of the SAPF controller is found very effective and adequate as compared with the $p-q$ theory.
\end{abstract}

KEYWORDS: 4-leg shunt active filter, harmonics isolator, distorted voltage conditions, self-tuning filter, fuzzy logic control.

\section{INTRODUCTION}

A connection of non-linear loads to the network, such as power electronics equipment in industrial activities and public consumers, causes an increase of current and voltage harmonics and leads to a lower power factor. This causes adverse effects in power systems, such as equipment overheating, motor vibration, excessive neutral currents. Two levels of APF are widely used to decrease harmonics and compensate the reactive power [1-3], these active power filters are limited in medium power domains. For high-power applications, the multilevel power converter structure was introduced as an alternative due to the difficulty of connecting only one power semiconductor switch directly, and a hybrid architecture has been also proposed to achieve high-power filters [4] 6]. A neutral-pointclamped inverter allows the shearing of equal voltage in each phase of series connected semiconductors. The instantaneous reactive power theory (IRP), presented by Akagi et al. [7, 8, has been successful to control the APF in 3-phase. Then, it was extended by Aredes et al. 9], for applications in 3-phase 4-wire systems. The IRP theory was mostly applied to calculate the compensating currents assuming mains voltage is ideal, but in industrial systems, the mains voltage may be distorted, therefore, the four-leg APF control does not gyield a good results with using the $p-q$ theory. The generation of the reference current mainly depends on the use of self-tuning filters (STF) to improve the performance of APF under conditions of non-ideal voltage. The STF extracts the main component directly from the electrical signals (distorted voltage and current) in the $\alpha-\beta$ reference frame power filter [10]. The APF control process has been the target of many recent researches and has used the traditional PI console a lot, but requires a precise mathematical model of the system and this is a difficult to achieve in the presence of an unbalanced nonlinear load and variations of parameters so we deal with that by using fuzzy logic [11, 12. The proposed fuzzy logic control scheme controls the harmonic current and DC voltage inverter in order to improve the performances of the four-leg three-level shunt APF. A comparison and evaluation between the proposed scheme and conventional $p-q$ theory are carried out by a computer simulation under unbalanced non-linear load and distorted voltage conditions. Simulation results demonstrate that the proposed scheme was found practical and good.

\section{System CONFIGURATION}

Figure 1, shows three-phase AC source connected in parallel to an active filter through four inductors, this filter has a three-phase voltage inverter using IGBT switches. To smooth the DC terminal voltage of the inverter, capacitors are used. To produce an unbalanced, harmonic, and reactive current in the phase currents, diode-rectifier nonlinear loads are used. The active filter inverter of $N$ levels requires $N-1$ capacitors and each capacitor passes a voltage equal to $V_{d c} / 2$, and $V_{d c}$ is the total voltage of the DC source. 


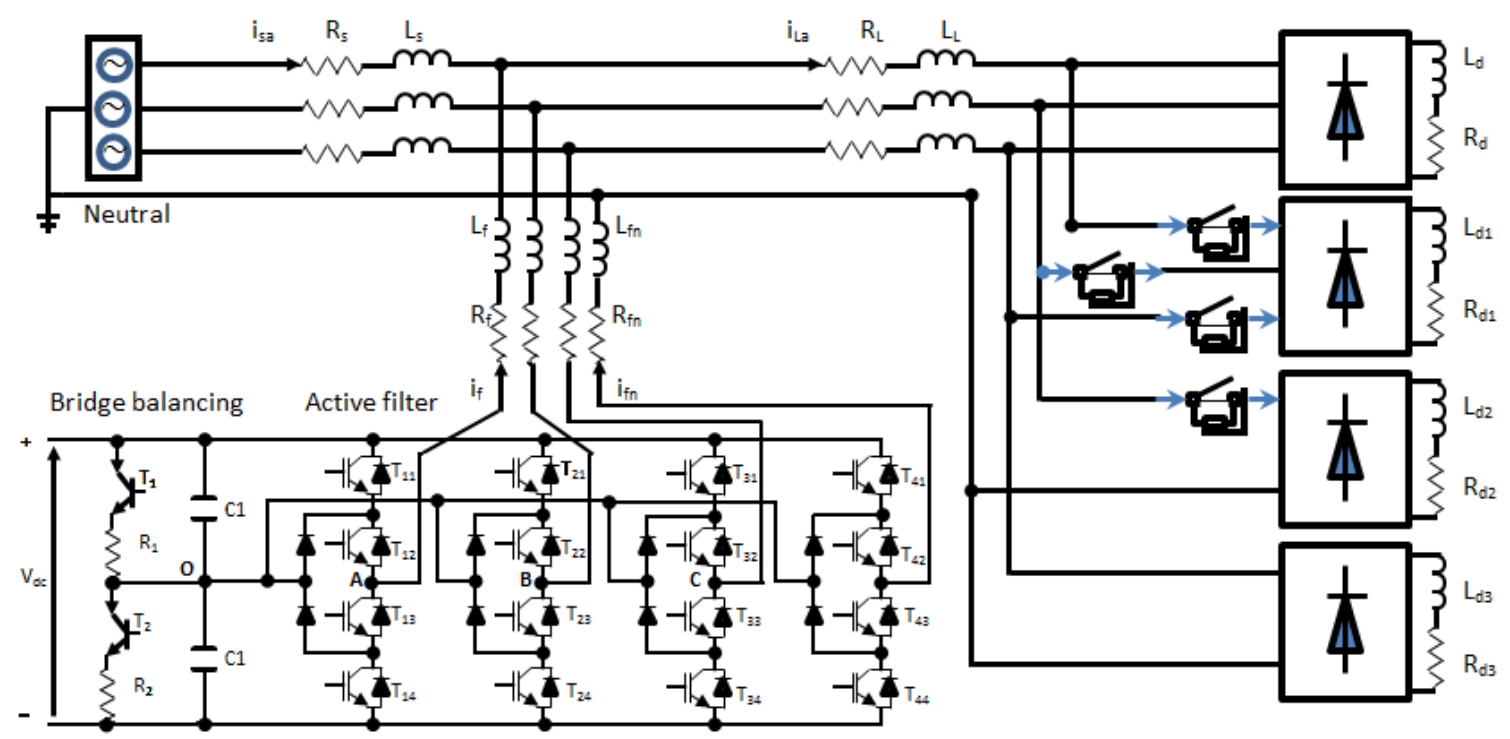

Figure 1. Power system configuration.

\begin{tabular}{llllll}
\hline$k_{i}$ & $T_{i 1}$ & $T_{i 2}$ & $T_{i 3}$ & $T_{i 4}$ & $V_{i 0}$ \\
\hline 1 & 1 & 1 & 0 & 0 & $V_{d c} / 2$ \\
0 & 0 & 1 & 1 & 0 & 0 \\
-1 & 0 & 0 & 1 & 1 & $-V_{d c} / 2$ \\
\hline
\end{tabular}

TABLE 1. Voltage states of one three-level phase leg.

Each switch pair $\left(T_{11}, T_{13}\right)$ represents a commutation cell; the two keys are arranged in a complementary manner. The inverter provides three voltage levels according to Equation (1):

$$
v_{i 0}=k_{i} \frac{v_{d c}}{2}
$$

Where, $v_{i o}$ is the phase-to-middle fictive point voltage, $k_{i}$ is the switching state variable $\left(k_{i}=1,0,-1\right)$, $v_{d c}$ is the DC source voltage, and $\mathrm{i}$ is the phase index $(i=a, b$ and $c)$. The three voltage values are shown in Table $1\left(v_{d c} / 2,0,-v_{d c} / 2\right)$.

\section{Reference CuRRent CALCUlation}

\subsection{THE $p-q$ THEORY}

The theory of instantaneous power [2, 13], which is briefly called the theory of $p-q$,depends on the instantaneous values of three-phase power systems with or without a neutral wire, it is valid in steady-state and transit-state processes, and in general, in the form of voltage and current waves. It works on the principle of the algebraic conversion (Clark transformation) of voltage and current from $a, b, c$ coordinates to $\alpha-\beta-0$ coordinates followed by a calculation of the power elements $p, q$ : The power components $p$ and $q$ can be written, using $\alpha-\beta$ voltages and currents, as:

$$
\left[\begin{array}{l}
v_{0} \\
v_{\alpha} \\
v_{\beta}
\end{array}\right]=\sqrt{\frac{2}{3}}\left[\begin{array}{ccc}
1 / \sqrt{2} & 1 / \sqrt{2} & 1 / \sqrt{2} \\
1 & -1 / 2 & -1 / 2 \\
0 & \sqrt{3} / 2 & \sqrt{3} / 2
\end{array}\right]\left[\begin{array}{l}
v_{s a} \\
v_{s b} \\
v_{s c}
\end{array}\right]
$$

$$
\left[\begin{array}{c}
i_{0} \\
i_{\alpha} \\
i_{\beta}
\end{array}\right]=\sqrt{\frac{2}{3}}\left[\begin{array}{ccc}
1 / \sqrt{2} & 1 / \sqrt{2} & 1 / \sqrt{2} \\
1 & -1 / 2 & -1 / 2 \\
0 & \sqrt{3} / 2 & \sqrt{3} / 2
\end{array}\right]\left[\begin{array}{c}
i_{a} \\
i_{b} \\
i_{c}
\end{array}\right]
$$

$$
\begin{gathered}
p_{0}=i_{0} v_{0} \\
p=i_{\alpha} v_{\alpha}+i_{\beta} v_{\beta} \\
q=i_{\beta} v_{\alpha}-i_{\alpha} v_{\beta}
\end{gathered}
$$

Where $p_{0}, p$ and $q$ are the instantaneous zerosequence power, instantaneous active power and instantaneous reactive power, respectively,

The power components $p$ and $q$ are related to the same $\alpha-\beta$ voltages and currents, and can be written together:

$$
\left[\begin{array}{l}
p \\
q
\end{array}\right]=\left[\begin{array}{cc}
v_{\alpha} & v_{\beta} \\
-v_{\beta} & v_{\alpha}
\end{array}\right]\left[\begin{array}{l}
i_{\alpha} \\
i_{\beta}
\end{array}\right]
$$

By reversing the equation (7), we can calculate the reference compensation currents in the $\alpha-\beta$ coordinates:

$$
\left[\begin{array}{c}
i_{\alpha}^{*} \\
i_{\beta}^{*}
\end{array}\right]=\frac{1}{v_{\alpha}^{2}+v_{\beta}^{2}}\left[\begin{array}{cc}
v_{\alpha} & -v_{\beta} \\
v_{\beta} & v_{\alpha}
\end{array}\right]\left[\begin{array}{c}
\tilde{p}-\hat{p}_{0} \\
q
\end{array}\right]
$$

With $\hat{p}_{0}$ being the fundamental component and $\tilde{p}$ being the alternative component. The representation of reference compensation currents in the $a, b, c$ coordinates requires a transformation inverse of (Equation 3) given by:

$$
\begin{gathered}
{\left[\begin{array}{c}
i_{a}^{*} \\
i_{b}^{*} \\
i_{c}^{*}
\end{array}\right]=\sqrt{\frac{2}{3}}\left[\begin{array}{ccc}
1 / \sqrt{(} 2) & 1 & 0 \\
1 / \sqrt{(2)} & -1 / 2 & \sqrt{(3) / 2} \\
1 / \sqrt{(2)} & -1 / 2 & \sqrt{(3) / 2}
\end{array}\right]\left[\begin{array}{c}
i_{0}^{*} \\
i_{\alpha}^{*} \\
i_{\beta}^{*}
\end{array}\right]} \\
i_{n}^{*}=-\left(i_{a}^{*}+i_{b}^{*}+i_{c}^{*}\right)
\end{gathered}
$$

The figure 2 gives the control block scheme of the $p-q$ theory for APF with four legs. 


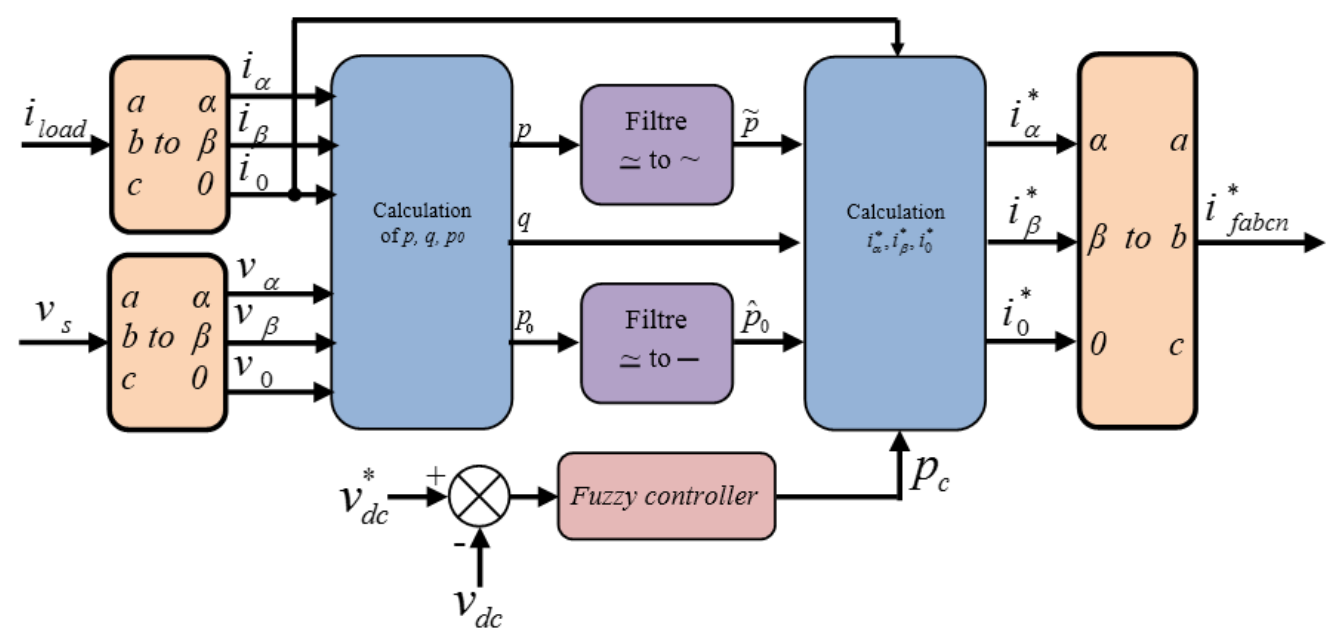

Figure 2. The $p-q$ theory control block diagram for the 4-leg APF.

\subsection{Proposed Method}

\subsubsection{SELF-TUNing FilTER}

To obtain the equivalent transfer function for integration within the synchronous reference frame (SRF), Hong-scok Song provided the following statement [14]:

$$
v_{x y}(t)=\exp (j w t) \int\left(\exp (-j w t) u_{x y}(t) d t\right)
$$

Where $u_{x y}$ and $v_{x y}$ are the instantaneous signals before and after the integration. We can express this equation by a Laplace transformation as follows:

$$
H(s)=\frac{v_{x y}(s)}{u_{x y}(s)}=\frac{s+j w}{s^{2}+w^{2}}
$$

To obtain the STF with a cut-off frequency $w_{c}$, we consider introducing the constant $k$ in the transfer function $H(s)$, so the previous transfer function $H(s)$ becomes:

$$
H(s)=\frac{v_{x y}(s)}{u_{x y}(s)}=\frac{(s+k)+j w_{c}}{(s+k)^{2}+w_{c}^{2}}
$$

By substituting the input signals $u_{x y}(s)$ by $x_{\alpha \beta}(s)$ and the output signals $v_{x y}(s)$ by $\hat{x}_{\alpha \beta}(s)$, the following equations can be written:

$$
\begin{aligned}
& \hat{x}_{\alpha}(s)=\frac{k}{s}\left[x_{\alpha}(s)-\hat{x}_{\alpha}(s)\right]-\frac{w_{c}}{s} \hat{x}_{\beta}(s) \\
& \hat{x}_{\beta}(s)=\frac{k}{s}\left[x_{\beta}(s)-\hat{x}_{\beta}(s)\right]-\frac{w_{c}}{s} \hat{x}_{\alpha}(s)
\end{aligned}
$$

The goal of using the STF is to extract the main component from distorted electrical signals, such as current and voltage, without changing the amplitude and without causing a phase shift. The selectivity of the filter could be increased by changing the value of $k$. The Figure 3 shows the STF block and the Figure 4 illustrate the bode diagram for different values of $k$ at $f_{c}=60 \mathrm{~Hz}$. It is clear that the phase delay corresponding to the desired frequency $\left(f_{c}\right)$ is equal to zero as shown in figure 4

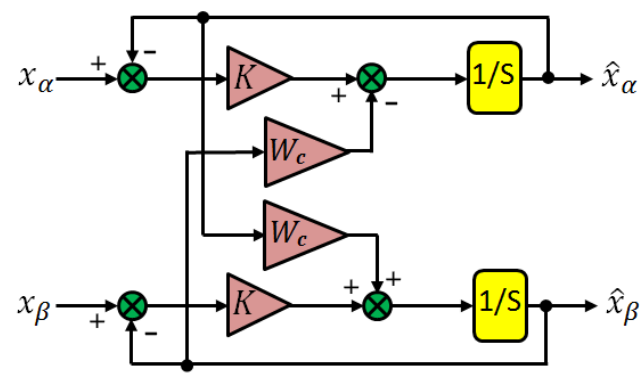

Figure 3 . Self-tuning filter tuned to the pulsation $w_{c}$.

\subsubsection{HARMONIC ISOLATOR}

The load currents $i_{L a}, i_{L b}$ and $i_{L c}$ are converted to the $\alpha-\beta$ axis according to the following relationship (Fig. 5):

$$
\left[\begin{array}{c}
i_{0} \\
i_{\alpha} \\
i_{\beta}
\end{array}\right]=\sqrt{\frac{2}{3}}\left[\begin{array}{ccc}
\frac{1}{\sqrt{2}} & \frac{1}{\sqrt{2}} & \frac{1}{\sqrt{2}} \\
1 & -\frac{1}{2} & -\frac{1}{2} \\
0 & \frac{\sqrt{3}}{2} & -\frac{\sqrt{3}}{2}
\end{array}\right]\left[\begin{array}{l}
i_{L a} \\
i_{L b} \\
i_{L c}
\end{array}\right]
$$

The currents $I_{\alpha}, I_{\beta}$ can be separated into DC and AC currents as follows:

$$
\begin{aligned}
i_{\alpha} & =\hat{i}_{\alpha}+\tilde{i}_{\alpha} \\
i_{\beta} & =\hat{i}_{\beta}+\tilde{i}_{\beta}
\end{aligned}
$$

When the STF extracts the fundamental component $\left(\hat{I}_{\alpha}, \hat{I}_{\beta}\right)$ directly from the currents $I_{\alpha}, I_{\beta}$ at a pulsation $w_{c}$, we calculate the harmonic component of the load by subtracting the input signals STF from the corresponding outputs (Fig. 5 ) and obtain AC currents $\left(\tilde{I}_{\alpha}, \tilde{I}_{\beta}\right)$ that correspond to the harmonic currents of the load currents $\left(i_{L a}, i_{L b}, i_{L c}\right)$ in the stationary reference frame. The source voltages $\left(v_{s a}, v_{s b}, v_{s c}\right)$ are converted in the same way, as follows:

$$
\left[\begin{array}{l}
v_{0} \\
v_{\alpha} \\
v_{\beta}
\end{array}\right]=\sqrt{\frac{2}{3}}\left[\begin{array}{ccc}
\frac{1}{\sqrt{2}} & \frac{1}{\sqrt{2}} & \frac{1}{\sqrt{2}} \\
1 & -\frac{1}{2} & -\frac{1}{2} \\
0 & \frac{\sqrt{3}}{2} & -\frac{\sqrt{3}}{2}
\end{array}\right]\left[\begin{array}{l}
v_{s a} \\
v_{s b} \\
v_{s c}
\end{array}\right]
$$



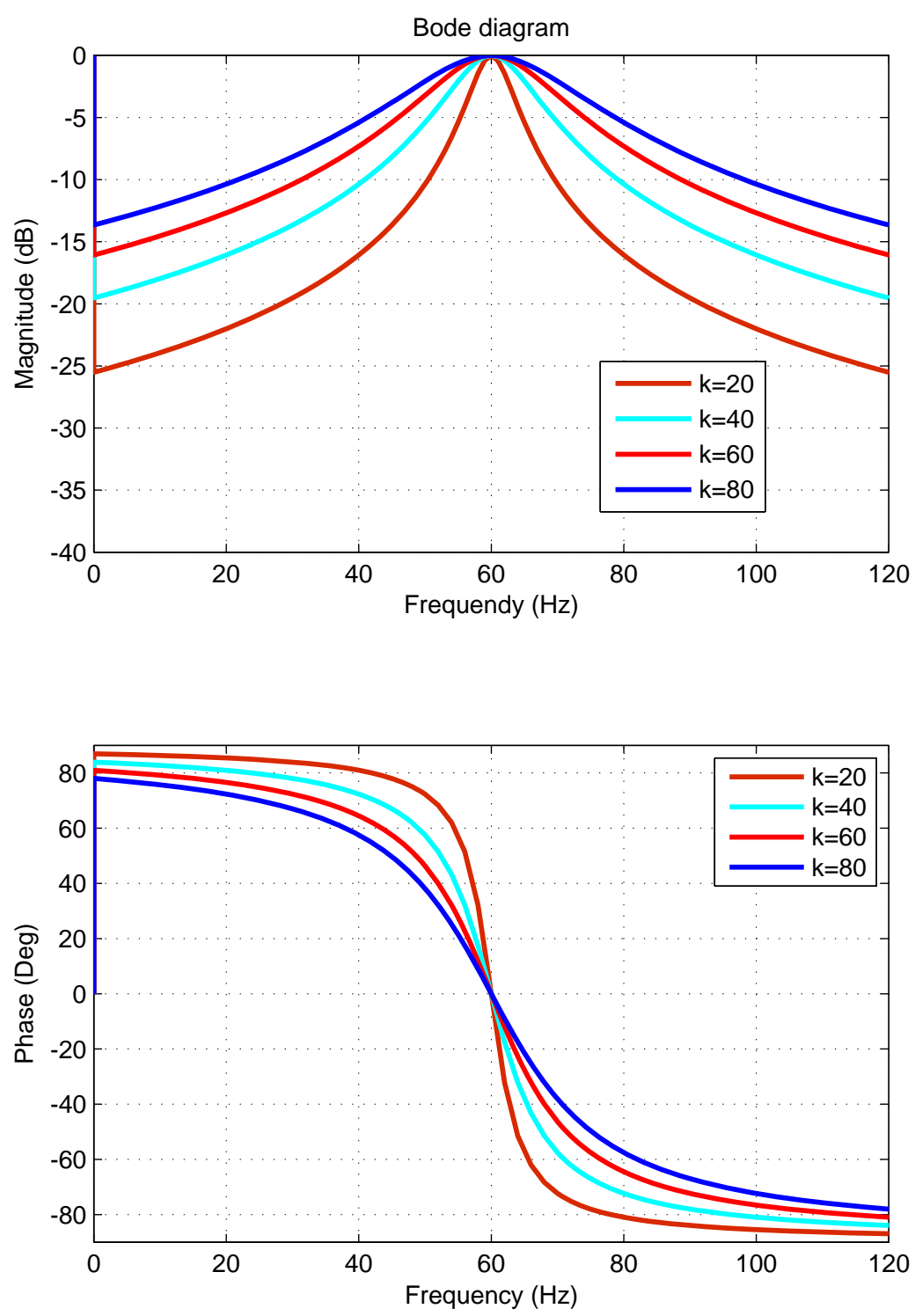

FIgURE 4. Bode diagram for the STF versus pulsation for different values of the parameter $k\left(f_{c}=60 \mathrm{~Hz}\right)$.

With the same preceding steps by which we obtained the harmonic component of the current, we obtain the harmonic component of the voltage. Then, we calculate the $p, q$ and $p_{0}$ powers as follows:

$$
\begin{gathered}
p=i_{\alpha} \hat{v}_{\alpha}+i_{\beta} \hat{v}_{\beta} \\
q=i_{\beta} \hat{v}_{\alpha}-i_{\alpha} \hat{v}_{\beta} \\
p_{0}=i_{0} v_{0}
\end{gathered}
$$

where

$$
p=\hat{p}+\tilde{p} ; q=\hat{q}+\tilde{q} ; p_{0}=\hat{p}_{0}+\tilde{p}_{0}
$$

With $\hat{p}, \hat{q}$ and $\hat{p}_{0}$ being the direct components, $\tilde{p}, \tilde{q}$ and $\tilde{p}_{0}$ being the alternative components. With the $\alpha-\beta$ voltages and currents, we can write the power components $\tilde{p}$ and $\tilde{q}$ as follows:

$$
\left[\begin{array}{c}
\tilde{p} \\
\tilde{q}
\end{array}\right]=\left[\begin{array}{cc}
v_{\alpha} & v_{\beta} \\
-v_{\beta} & v_{\alpha}
\end{array}\right]\left[\begin{array}{c}
\tilde{i}_{\alpha} \\
\tilde{i}_{\beta}
\end{array}\right]
$$

After reversing expression (24) and inserting the powers to be compensated $\left(\left(\tilde{p}-\hat{p}_{0}\right)\right.$ and $\left.q\right)$, we get the reference compensating currents in the $\alpha-\beta$ coordinates. For regulating DC bus voltage, the active power required $p_{c}$ is added to the alternative component of instantaneous real power $\tilde{p}$ (Figure. 5). The reference currents' $i_{\alpha \beta 0}^{*}$ in $\alpha-\beta$ coordinates are calculated as follow:

$$
i_{\alpha}^{*}=\frac{\hat{v}_{\alpha}}{v_{\alpha}^{2}+v_{\beta}^{2}}\left(\tilde{p}+p_{c}-\hat{p}_{0}\right)-\frac{\hat{v}_{\beta}}{v_{\alpha}^{2}+v_{\beta}^{2}} q
$$




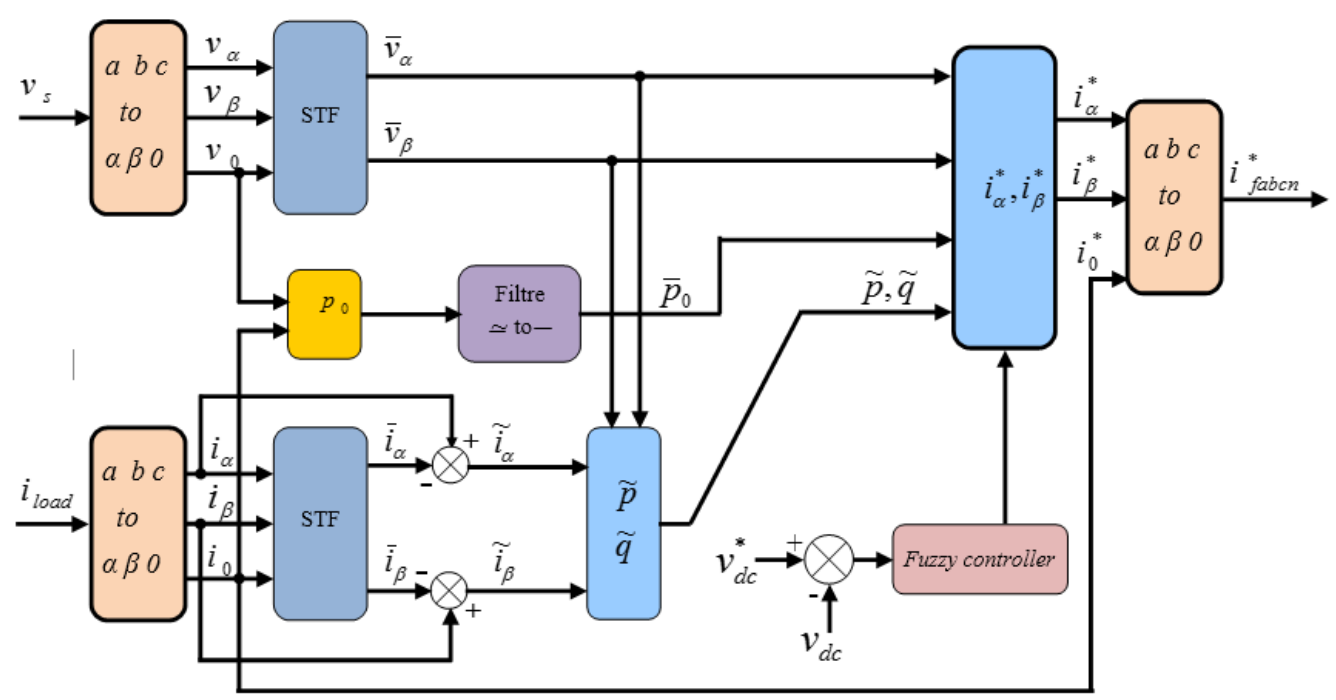

FiguRE 5. STF block diagram with harmonic isolator.

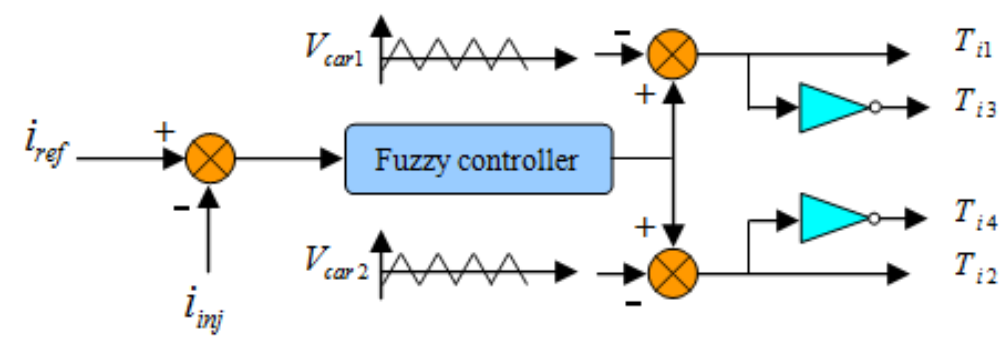

FigURE 6. PWM block diagram of currents control.

$$
\begin{gathered}
i_{\beta}^{*}=\frac{\hat{v}_{\alpha}}{v_{\alpha}^{2}+v_{\beta}^{2}}\left(\tilde{p}+p_{c}-\hat{p}_{0}\right)+\frac{\hat{v}_{\alpha}}{v_{\alpha}^{2}+v_{\beta}^{2}} q \\
i_{0}^{*}=i_{0}
\end{gathered}
$$

Then, the filter reference currents in the $a-b-c$ coordinates are defined by:

$$
\begin{gathered}
{\left[\begin{array}{c}
i_{f a}^{*} \\
i_{f b}^{*} \\
i_{f c}^{*}
\end{array}\right]=\sqrt{\frac{2}{3}}\left[\begin{array}{ccc}
\frac{1}{\sqrt{2}} & 1 & 0 \\
\frac{1}{\sqrt{2}} & -\frac{1}{2} & \frac{\sqrt{3}}{2} \\
\frac{1}{\sqrt{2}} & -\frac{1}{2} & -\frac{\sqrt{3}}{2}
\end{array}\right]\left[\begin{array}{c}
i_{0}^{*} \\
i_{\alpha}^{*} \\
i_{\beta}^{*}
\end{array}\right]} \\
i_{f n}^{*}=-\left(i_{f a}^{*}+i_{f b}^{*}+i_{f c}^{*}\right)
\end{gathered}
$$

Figure 5 shows the block diagram of the STF.

\section{INVERTER CONTROL USING PWM}

The fuzzy logic controller is applied, where its input is the difference between the injected current and the reference current and its output are the reference voltages of the inverter after its comparison with two triangular signals, which have the same frequency and phase [15, 16. The table 2 summarizes the switching states for one phase leg of a three-level inverter. In Figure 6, a current control block diagram is shown.

\begin{tabular}{ccccc}
\hline Output voltage & $T_{i 1}$ & $T_{i 2}$ & $T_{i 3}$ & $T_{i 4}$ \\
\hline$V_{d c} / 2$ & 1 & 1 & 0 & 0 \\
0 & 0 & 1 & 1 & 0 \\
$-V_{d c} / 2$ & 0 & 0 & 1 & 1 \\
\hline
\end{tabular}

TABLE 2. The switching states.

\section{FUZZY LOGIC CONTROL APPLICATION}

Figure 7 shows the diagram of the fuzzy logic controller with two inputs and one output. The inputs are the difference between the reference current and the injected current (Error: $e=i_{r e f}-i_{f}$ ) and its derivative $(d e)$, respectively. The output is the command (cde).

\section{ACTIVE POWER FILTER CURRENT CONTROL}

The goal is to replace conventional controllers with fuzzy logical ones in order to obtain a sinusoidal source current that is in phase with the source voltage [17]. The fuzzy control properties are as follows:

- Three fuzzy sets for each input (Positive, Zero, Negative)

- Five fuzzy sets for the director (Positive Large, Positive, Zero, Negative, Negative Large). 


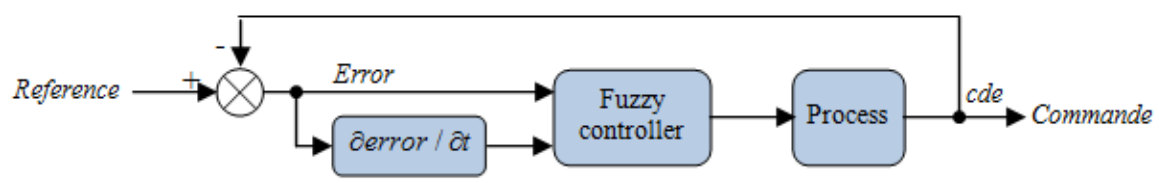

FiguRE 7. Fuzzy controller synoptic diagram.

\begin{tabular}{llllllll}
\hline $\begin{array}{c}e \\
\delta e\end{array}$ & $N L$ & $N M$ & $N S$ & $Z E$ & $P S$ & $P M$ & $P L$ \\
\hline$N L$ & $N L$ & $N L$ & $N L$ & $N L$ & $N M$ & $N S$ & $Z E$ \\
$N M$ & $N L$ & $N L$ & $N L$ & $N M$ & $N S$ & $Z E$ & $P S$ \\
$N S$ & $N L$ & $N L$ & $N M$ & $N S$ & $Z E$ & $P S$ & $P M$ \\
$Z E$ & $N L$ & $N M$ & $N S$ & $Z E$ & $P S$ & $P M$ & $P L$ \\
$P S$ & $N M$ & $N S$ & $Z E$ & $P S$ & $P M$ & $P L$ & $P L$ \\
$P M$ & $N S$ & $Z E$ & $P S$ & $P M$ & $P L$ & $P L$ & $P L$ \\
$P L$ & $N L$ & $N M$ & $N S$ & $Z E$ & $P S$ & $P M$ & $P L$ \\
\hline
\end{tabular}

TABLE 3. Fuzzy control rules.

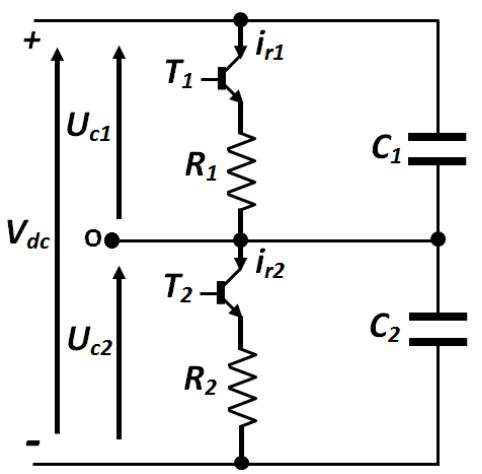

Figure 8. Structure of the bridge balancing.

\begin{tabular}{|c|c|}
\hline \multicolumn{2}{|l|}{ Source } \\
\hline System frequency & $60 \mathrm{~Hz}$ \\
\hline System voltage & $230 \sqrt{2} V_{\max }$ \\
\hline Impedance: $R_{s}, L_{s}$ & $0.5 \mathrm{~m} \Omega, 0.015 \mathrm{mH}$ \\
\hline \multicolumn{2}{|l|}{ 4-Leg shunt APF } \\
\hline DC-link voltage: $V_{d c}$ & $800 \mathrm{~V}$ \\
\hline DC capacitor: $C_{1}, C_{2}$ & $70 m F$ \\
\hline Switching frequency: & $5 K h z$ \\
\hline AC side filter: $R_{f}, L_{f}$ & $5 \mathrm{~m} \Omega, 0.068 \mathrm{mH}$ \\
\hline$R_{f n}, L_{f n}$ & $5 \mathrm{~m} \Omega, 0.55 \mathrm{mH}$ \\
\hline \multicolumn{2}{|l|}{ Load } \\
\hline Inductor: $L_{d}, L_{d 1}$ & $2 m H$ \\
\hline Resistor: $R_{d}, R_{d 1}$ & $0.6 \Omega, 3 \Omega$ \\
\hline Inductor: $L_{d 2}, L_{d 3}$ & $1 m H$ \\
\hline Resistor: $R_{d 2}, R_{d 3}$ & $3 \Omega, 2.75 \Omega$ \\
\hline Inductor: $L_{L}, L_{L 1}, L_{L 2}$ & $0.05 \mathrm{mH}$ \\
\hline Resistor: $R_{L}, R_{L 1}, R_{L 2}$ & $1.2 \mathrm{~m} \Omega$ \\
\hline
\end{tabular}

- Use the 'Minimum' operator and the 'centroïd' method.

- The knowledge of fuzzy rules is based on the error sign $(e)$. If the derivative $(d e)$ becomes positive, the error increases $\left(i_{r e f}>i_{f}\right)$. If it becomes negative, the error decreases $\left(i_{r e f}<i_{f}\right)$. If the derivative becomes equal to zero, the error is fixed $\left(i_{r e f}=i_{f}\right)$.

\section{DC CAPACITORS VOLTAGES STABILIZATION}

To achieve the balance of two input voltages, improve the performance of active power filters and avoid a potential drift of the neutral point (NP), a stabilization bridge system shown in Fig 8 is inserted. If the voltage $U_{c x}$ becomes higher than the reference voltage $U_{\text {ref }}$ (400volts), the transistor $T_{x}$ is opened to slow the charging of the capacitor $C_{x}$, and the transistor is controlled as follows:

$U_{c x}-U_{\text {cref }}=\Delta_{x}$ with $x=1,2$.

if $\Delta_{x}>0$ then $T_{x}=1$ with $i_{r x}=T_{x} \frac{U_{c x}}{R_{x}}$.

Else $T_{x}=0$.

\section{DC CAPACITOR VOLTAGE CONTROL}

To reduce the deformation of harmonic current and improve the performance of the active filter, we use the Fuzzy Logic Control Unit, relying on the error handling of the voltage and its derivative, to control the inverter voltage of the capacitor. Here, we use 49 rules as shown in Table 3 .

\section{Simulation PARAmeters}

We use the parameters summarized in the Table 4 for simulation.

TABLE 4. Simulation parameters. 

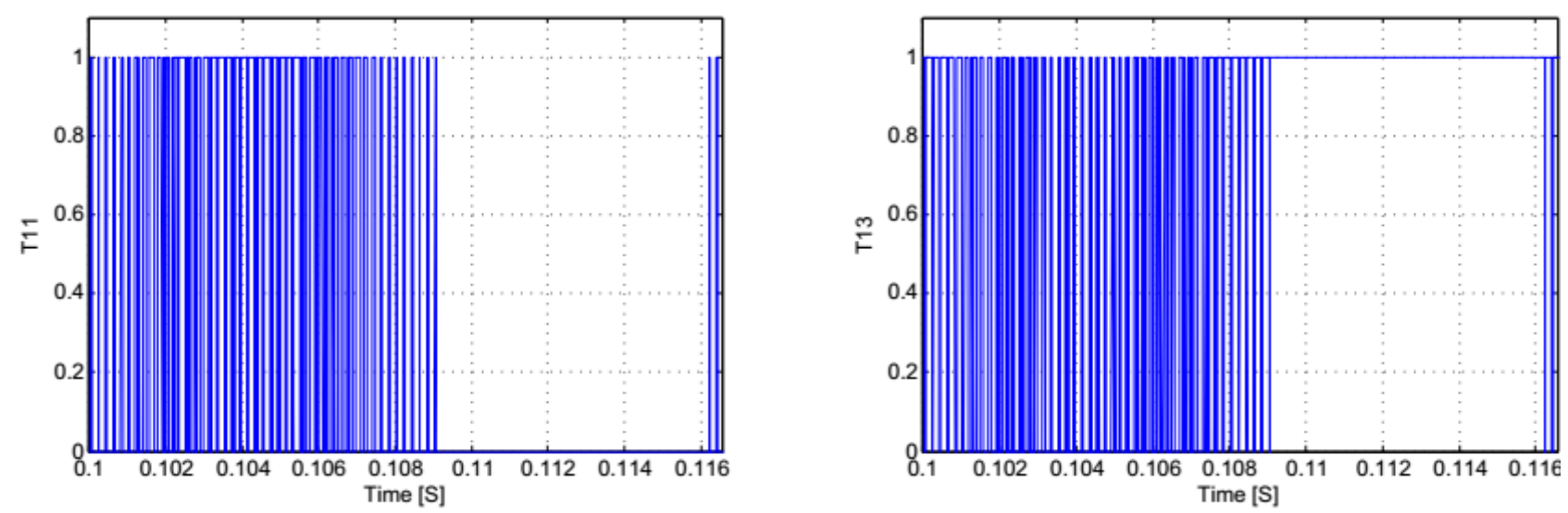

FIGURE 9. Switching pulses of APF arms $\left(T_{11}, T_{13}\right)$.

\section{Results AND Discussions}

The harmonic current of the 4-Leg 3-level APF was examined as well as the reactive power compensation, load current balance and neutral current elimination by the proposed method and $p-q$ method under deformed voltage and non-linear load conditions. Two methods are applied to calculate the reference current, the $p-q$ theory and the STF, method based on the topology shown in Figure 1. The sequence of the connection of the nonlinear loads is presented as follows: A single-phase nonlinear load is connected in the phase (c) to create an unbalanced nonlinear load at $0 \mathrm{~s}$ and at $0.2 \mathrm{~s}$ : A three-phase nonlinear load is connected to increase the current load and a single-phase nonlinear load is also connected in phase (b) to create an unbalanced nonlinear load. All these sequences of connections aim to evaluate the dynamic performance and to show the extent of the system's interaction.

The advantages of a multi-level inverter are evident from the switching signal presented in Figure 9 where the low frequency commutation process is shown. Note that the supply voltage is not sinusoidal and includes a 5 th harmonic component $(\mathrm{THD}=$ $11.10 \%$ ), as shown in Figure 10 and the total harmonic distortion of the current source $i_{s a}$ before filtering is equal to $(\mathrm{THD}=22.30 \%)$ see Figure 11 .

By applying the $p-q$ theory, the harmonic distortion coefficient of $i_{s a}$ is reduced to $(8.62 \%)$ after filtering, as shown in Figure 12. In Figure 13. we present the value of the harmonic distortion coefficient of $i_{s a}$ obtained by the proposed method after filtering, it is a very acceptable value according to the IEEE 519-2014 and IEC 61000-3 harmonic standards limit.

As for the neutral current, we eliminate it in two different ways, $p-q$ theory and the proposed method, as can be seen in Figure 14. The harmonic isolation and fuzzy logic controller allow a simultaneous compensation of the reactive power and harmonic current. The current and voltage signal obtained are in phase under the distorted voltage and non-linear and unbalanced load conditions, this is illustrated in Figure 15.
Figure 16 shows the harmonic currents obtained using the self-tuning filters that improved the quality of the reference currents. Figure 17 shows the line-to-line output voltage and illustrates the three levels with the PDPWM. Figure 18 shows the shape of the voltage between the two ends of the stabilization bridge, which is free from ripples, and it shows the two potentials $\left(U_{c 1} ; U_{c 2}\right)$ where it stabilizes around the value of 400 volts. Load current balancing and harmonic current suppression results are shown in Figure 19 (a, b, c, d) for the $p-q$ theory and the proposed method under distorted voltages and unbalanced non-linear load conditions for 4-Leg 3-level APF. The Figure 19a shows the distorted voltage $\left(v_{a b c}\right)$ and figure $19 \mathrm{~b}$ shows the load currents $\left(i_{L a b c}\right)$, it is clear that the load current $\left(i_{L c}\right)$ of the phase $(\mathrm{c})$ is affected by the single nonlinear load connected at the same phase. At $0.2 s$ the load currents $\left(i_{\text {Labc }}\right)$ are affected by three-phase nonlinear loads connected at the same moment $(0.2 s)$. As for the Figure $19 k$, the $p-q$ theory was applied; however, the source signal currents are still slightly distorted $(T H D=8.62 \%)$ despite the response time being only $0.2 s$. As for the proposed method (Fig. $19 \mathrm{~d}$ ), we notice a good shape $(T H D=1.89 \%)$ of the source currents and an appropriate response at the time of the load change $(0.2 s)$, which gives it a slight edge over the $p-q$ theory.

\section{Conclusion}

This article used a fuzzy logic controller to improve the control and performance of an active power filter under deformed voltage conditions and an unbalanced non-linear load. We adopted a modified version of PDPWM and $p-q$ theory to generate switching signals in the context of improving the creation of the reference current. Simulation results demonstrate that all of the following points have been effectively accomplished even under conditions of deformed voltage and an unbalanced and non-linear load:

- Filtering the current harmonics;

- Reactive power compensation; 

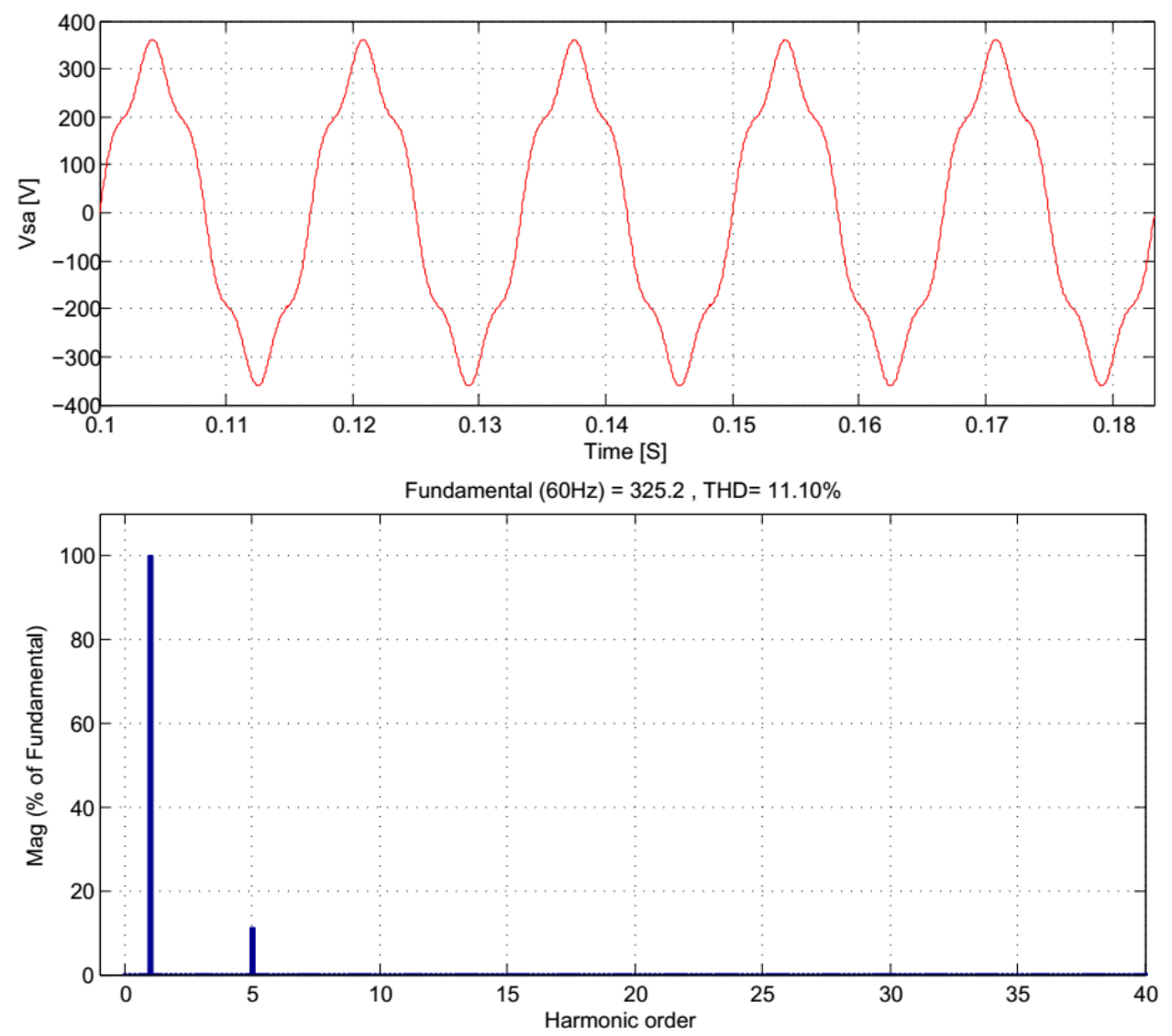

FigurE 10. Waveform of supply voltage $v_{s a}$.
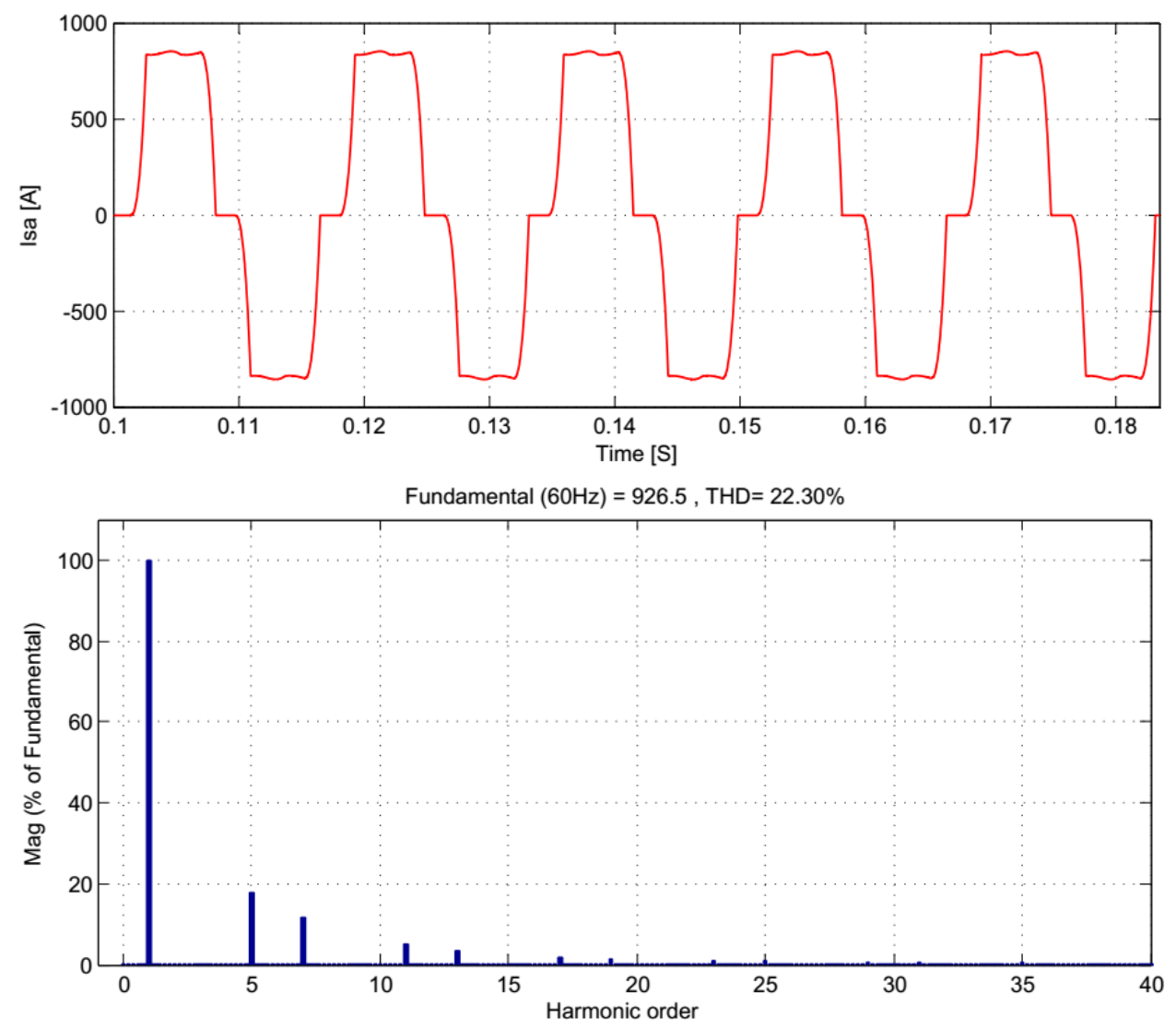

FIGURE 11. Waveform of supply current $i_{s a}$ without filtering. 

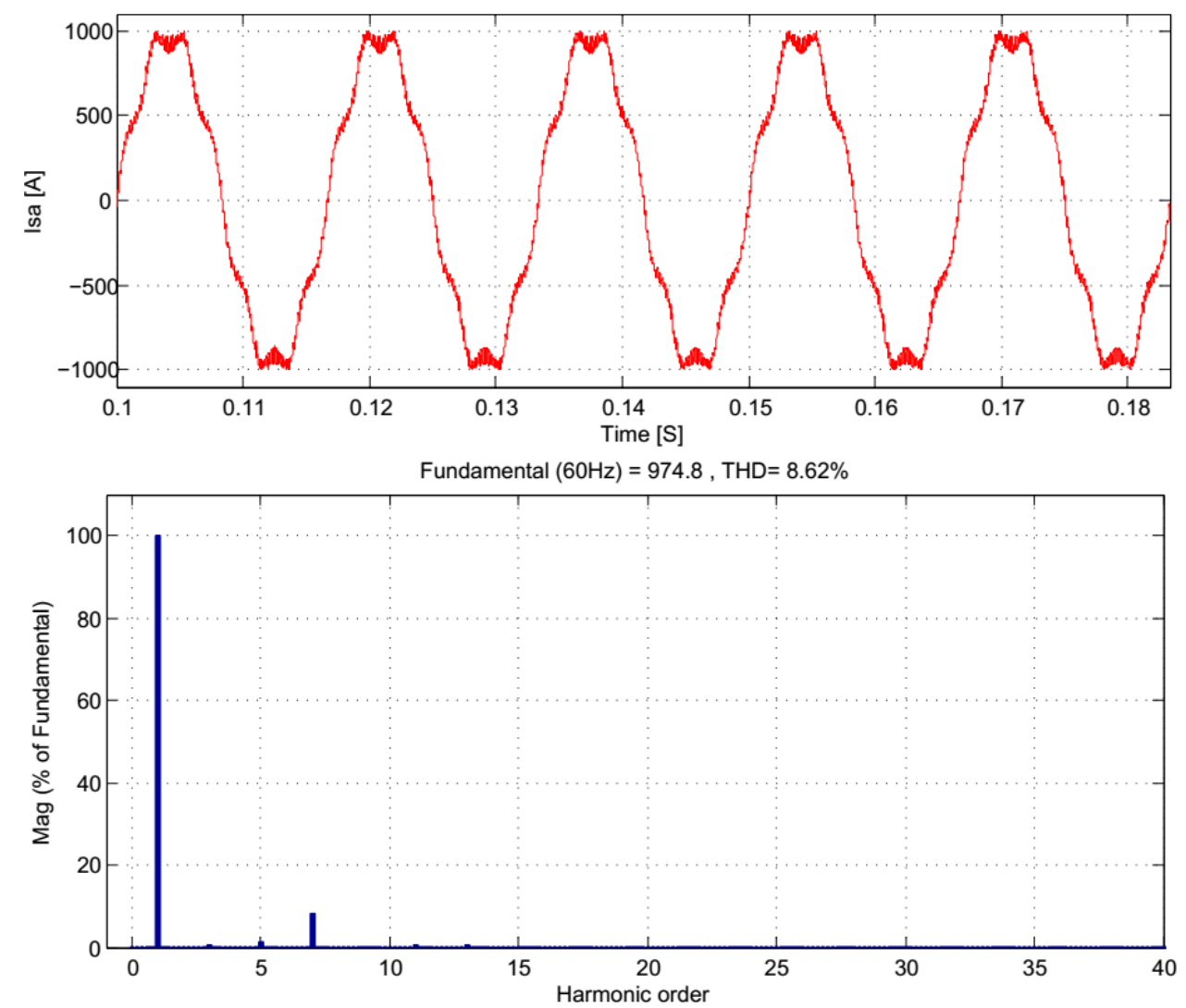

FiguRE 12. Waveform of supply current $i_{s a}$ after filtering using $p-q$ theory.
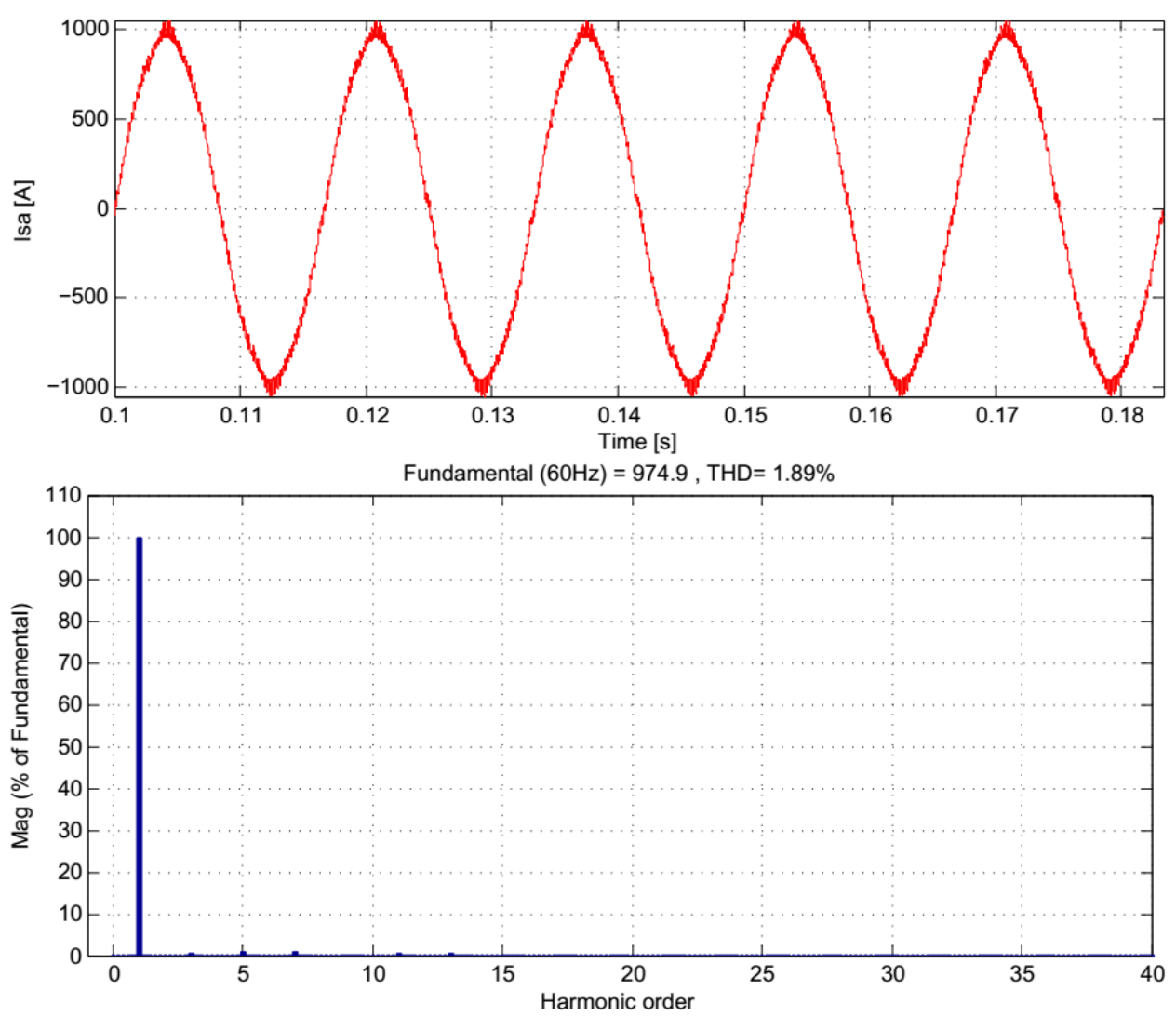

FIGURE 13. Waveform of supply current $i_{s a}$ with filter using proposed method. 

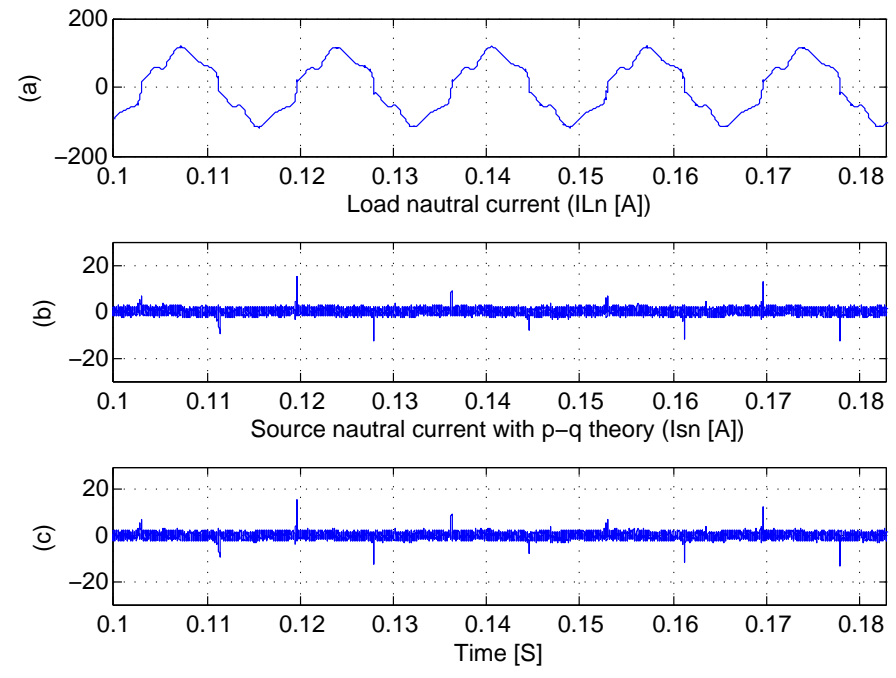

Source nautral current with the proposed method (Isn [A]

Figure 14. Neutral current elimination.

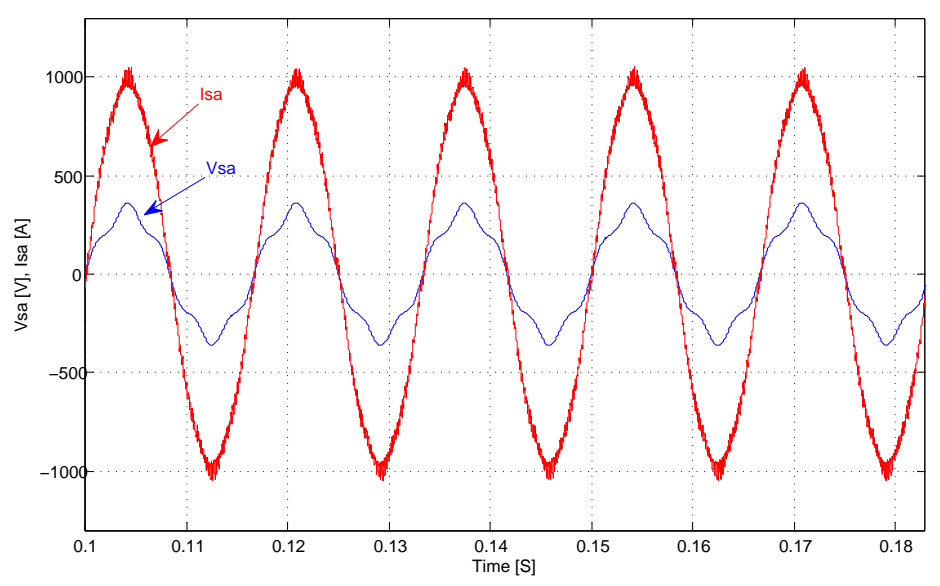

Figure 15. Power factor correction.

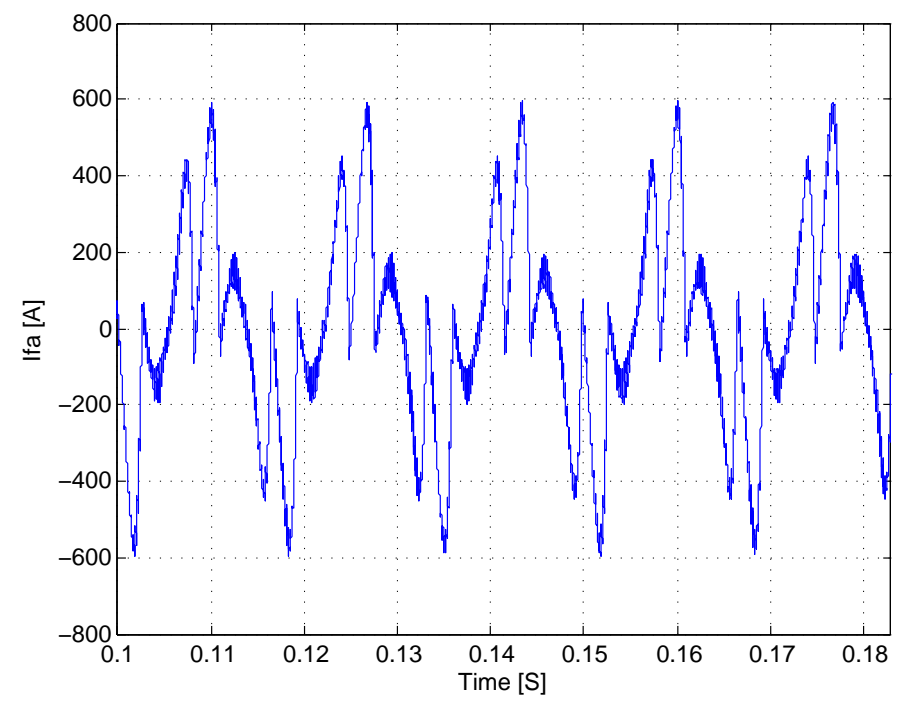

Figure 16. Active filter current. 


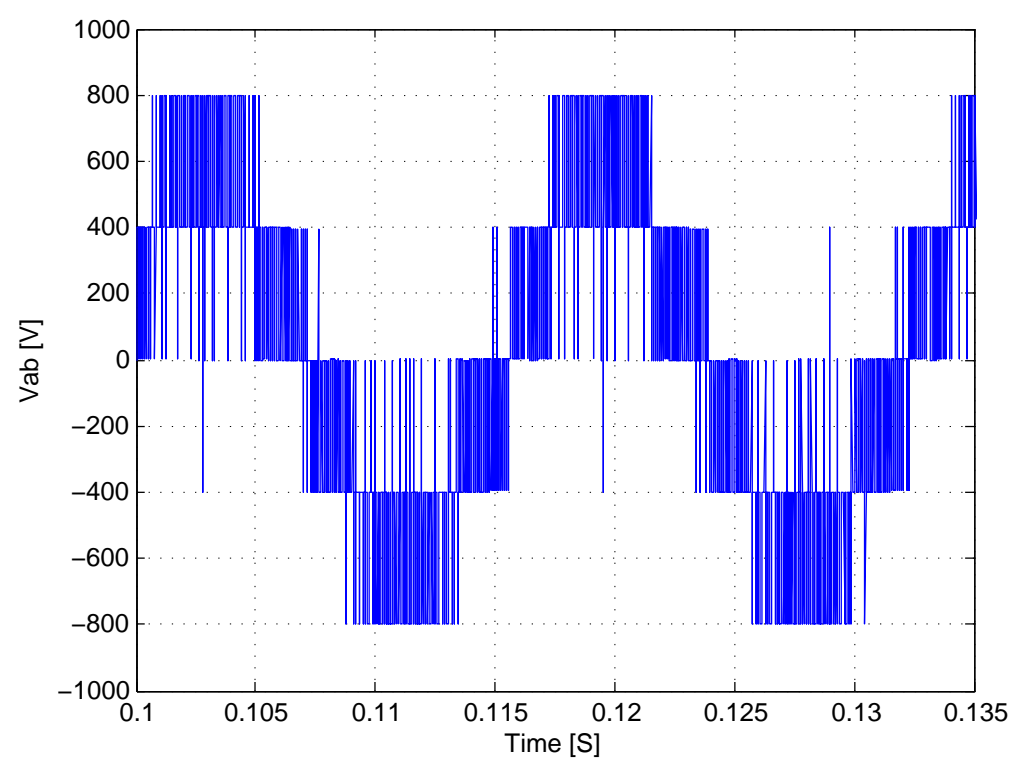

FIGURE 17. APF output voltage $V_{a b}$ line-to-line.
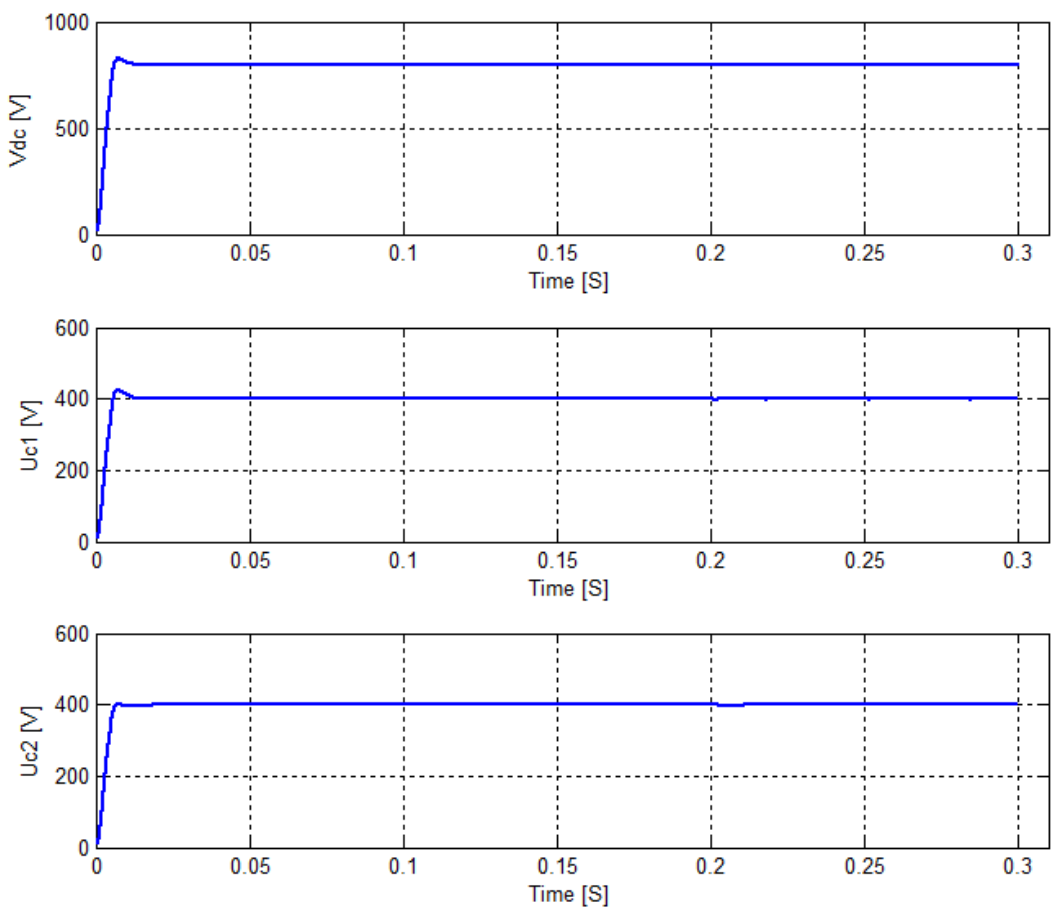

Figure 18. DC voltage: (top) $V_{d c}$, (middle) $U_{c 1}$, (bottom) $U_{c 2}$. 

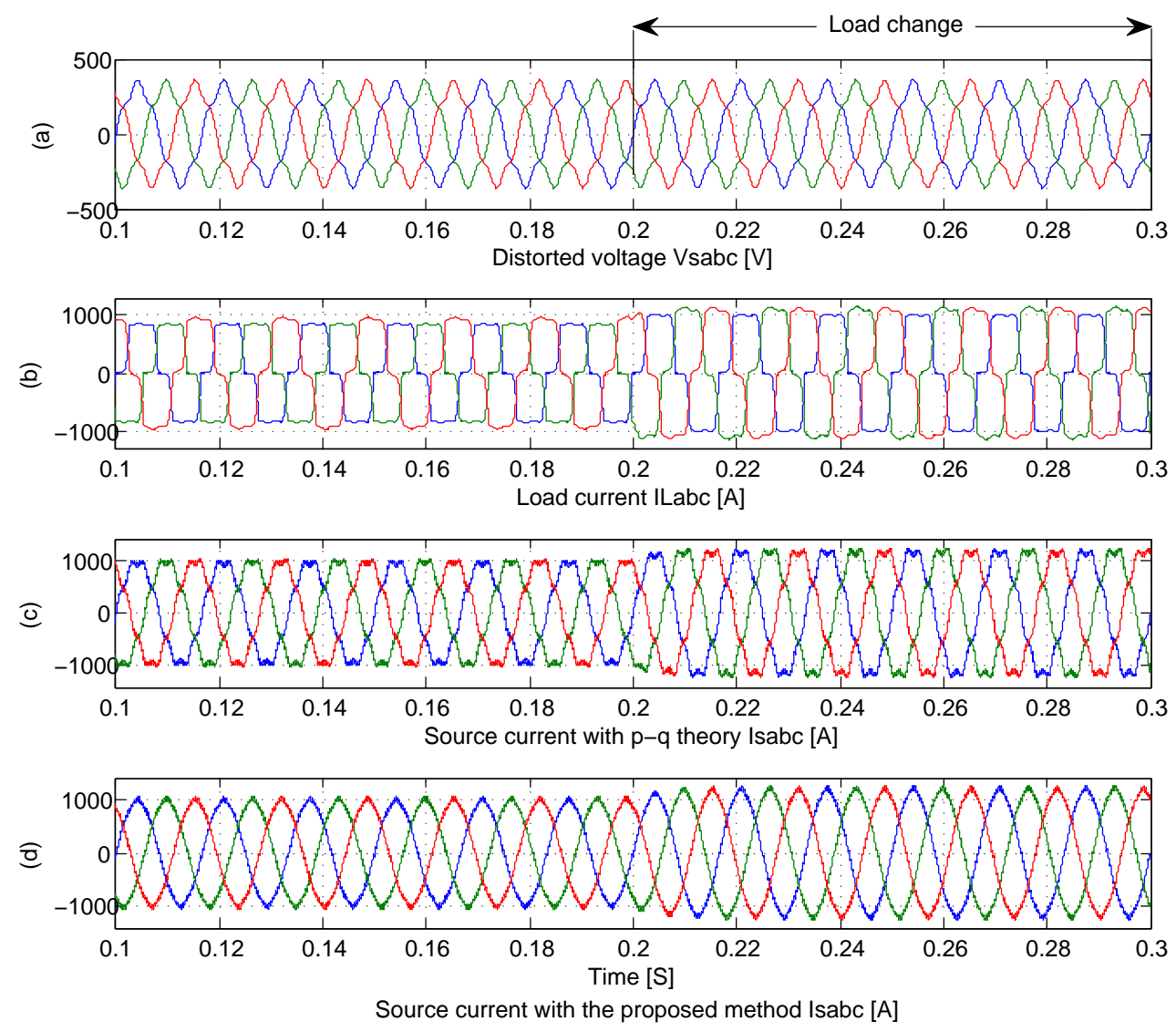

FiguRE 19. Harmonic currents filtering under unbalanced non-linear load and distortion voltage conditions.

- Load balancing current;

- Elimination of excessive neutral current;

- Under both static and dynamic operating conditions, the method shows excellent results.

The use of a self-tuning filter leads to good improvements as it completely extracts harmonic currents in distorted conditions. In conclusion, the results showed the important advantages of using the STF and fuzzy logic in controlling the filter, such as improving the waveform and reducing harmonic distortion, as well as the possibility of using it in high-power applications.

\section{REFERENCES}

[1] A. Benaissa, B. Rabhi, A. Moussi. Power quality improvement using fuzzy logic controller for five-level shunt active power filter under distorted voltage conditions. Springer J 8(2):212-220, 2014. https://doi.org/10.1007/s11708-013-0284-4

[2] A. Benaissa, B. Rabhi, A. Moussi, M. Benkhoris. Fuzzy logic controller for three phase four-leg five-level shunt active power filter under unbalanced non-linear load and distorted voltage conditions. Springer J 5(3):361-370, 2014. https://doi.org/10.1007/s13198-013-0176-3.

[3] H. Akagi. Trend in active power line conditioners. IEEE Transactions on Power Electronics J 9(3):263-268, 1994. https://doi.org/10.1109/63.311258.
[4] H. K.Chiang, B. R.Lin, K. T.Yang, K. W.Wu. Hybrid active power filter for power quality compensation. International Conference on Power Electronics and Drive Systems (PEDS), Kuala Lumpur, Malaysia pp. 949-954, 2005. [28 Nov-1 Dec], https://doi.org/10.1109/PEDS.2005.1619824.

[5] X. Wanfang, L. An, W. Lina. Development of hybrid active power filter using intelligent controller. Automation of Electric Power System J 26(10):49-52, 2003.

[6] O. Vodyakho, T. Kim, S. Kwak. Three-level inverter based active power filter for the three-phase, four-wire system. IEEE Power Electronics Specialists Conference (PESC2008), Rhodes, Greece pp. 1874-1880, 2008. [June 15-19], https://doi.org/10.1109/PESC.2008.4592217.

[7] G. W.Chang, C. M.Yeh. Optimization-based strategy for shunt active power filter control under non-ideal supply voltages. IEE Electric Power Applications $J$ 152(2):182-190, 2005. https://doi.org/10.1049/ip-epa:20045017.

[8] M. I.M.Montero, E. R.Cadaval, F. B.Gonzalez. Comparison of control strategies for shunt active power filters in three-phase four-wire systems. IEEE Transactions on Power Electronics J 22(1):229-236, 2007. https://doi.org/10.1109/TPEL.2006.886616.

[9] T. C.Green, J. H.Marks. Control techniques for active power filters. IEE Electric Power Applications J 
152(2):369-381, 2005.

https://doi.org/10.1049/ip-epa:20040759

[10] M. Abdusalama, P. Poure, S. Karimi, S. Saadate. New digital reference current generation for shunt active power filter under distorted voltage conditions. Electric Power Systems Research J 79(5):759-765, 2009. https://doi.org/10.1016/j.epsr.2008.10.009

[11] A. Hamadi, K. El-Haddad, S. Rahmani, H. Kankan. Comparison of fuzzy logic and proportional integral controller of voltage source active filter compensating current harmonics and power factor. IEEE International Conference on Industrial Technology (ICIT), Hammamet, Tunisia pp. 645-650, 2004. [Dec 8-10], https://doi.org/10.1109/ICIT.2004.1490149.

[12] A. H.Bhat, P. Agarwal. A fuzzy logic controlled three-phase neutral point clamped bidirectional pfc rectifier. IEEE International Conference on Information and Communication Technology in Electrical Sciences (ICTES2007), Tamil Nadu, India pp. 238-244, 2007. [Dec 20-22], https://doi.org/10.1049/ic:20070617.

[13] J. Afonso, C. Couto, J. Martins. Active filter with control based on the p-q theory. IEEE Industrial Electrons Society Newsletter J 47(3):5-10, 2000.
[14] S. Hong-Scok. Control scheme for pwm converter and phase angle estimation algorithm under voltage unbalanced and/or sag condition. PhD thesis, Postecch university, Republic of Korea (South) 2000.

[15] B. P.McGrath, D. G.Holmes. Multicarrier pwm strategies for multilevel inverters. IEEE Transactions on Industrial Electronics J 49(4):858-867, 2002. https://doi.org/10.1109/TIE.2002.801073.

[16] A. Jouanne, S. Dai, H. Zhang. A multilevel inverter approach providing dc-link balancing, ride-through enhancement, and common mode voltage elimination. IEEE Transactions on Industrial Electronics J 49(4):739745, 2002. https://doi.org/10.1109/TIE.2002.801233

[17] S. Saad, L. Zellouma, L. Herous. Comparison of fuzzy logic and proportional controller of shunt active filter compensating current harmonics and power factor. 2nd International Conference on Electrical Engineering Design and Technology (ICEEDT08), Hammamet, Tunisia pp. 8-10, 2008. [Nov. 3-5]. 